\title{
3 Research Square

\section{Complement Protein C3 Loss leads to Locomotor Deficits and Altered Cerebellar Internal Granule Cell In Vitro Synaptic Protein Expression in C57BL/6 mice}

\section{Stephen J. Bonasera ( $\nabla$ sbonasera@unmc.edu )}

University of Nebraska Medical Center College of Pharmacy https://orcid.org/0000-0001-6808-2821

Nicholas W. DeKorver

University of Nebraska Medical Center

Tammy R. Chaudoin

University of Nebraska Medical Center

\section{Gang Zhao}

University of Nebraska Medical Center

\section{Dong Wang}

University of Nebraska Medical Center

Jyothi Arikkath

Monroe Meyer Institute, University of Nebraska Medical Center

\section{Research Article}

Keywords: complement 3, gait speed, bone density, microtomography, grip strength, ataxia, cerebellum, internal granule cell, Vglut1, Vgat

DOI: https://doi.org/10.21203/rs.3.rs-303802/v1

License: (1) (1) This work is licensed under a Creative Commons Attribution 4.0 International License. Read Full License 


\section{Abstract}

Complement 3 (C3) expression is increased in the cerebellum of aging mice that demonstrate locomotor impairments and increased excitatory synapse density. However, C3 regulation of locomotion, as well as $\mathrm{C} 3$ roles in excitatory synapse function, remain poorly understood. Here, we demonstrate that constitutive loss of C3 function in mice evokes a locomotor phenotype characterized by decreased speed, increased active state locomotor probability, and gait ataxia. C3 loss does not alter metabolism or body mass composition. No evidence of significant muscle weakness or degenerative arthritis was found in C3 knockout mice to explain decreased gait speeds. In an enriched primary cerebellar granule cell culture model, loss of C3 protein results in increased excitatory synaptic density and increased response to $\mathrm{KCl}$ depolarization. Our analysis of excitatory synaptic density in the cerebellar internal granule cell and molecular layers did not demonstrate increased synaptic density in vivo, suggesting the presence of compensatory mechanisms regulating synaptic development. Functional deficits in C3 knockout mice are therefore more likely to result from altered synaptic function and/or connectivity than gross synaptic deficits. Our data demonstrate a novel role for complement proteins in regulation of locomotor function and proper organization of cerebellar neuronal networks.

\section{Introduction}

The complement system is a group of more than 30 proteins first appreciated to be important mediators of innate immunity. Many complement proteins are widely expressed within the CNS [1-7], and regulate critical neuronal functions, including migration, proliferation, adult neurogenesis, and synaptic maintenance.

Complement 3 (C3) is a multifunctional protein with catalytic, regulatory, and cell surface receptor activities. Previous studies suggest that C3 plays critical roles in CNS development, synaptic plasticity, and behavior [8-11]. For example, C3a receptors (C3aRs) regulate in vitro neuroprogenitor cell differentiation and migration [12]. C3 knockout decreases neurogenesis in the subventricular zone [13], while both C3 knockout and knockdown evoke clear neuronal migration deficits from the subventricular zone into the cortex [14] mediated by $\mathrm{C} 3 \mathrm{aRs}$ and downstream Rac1 activity reduction [15]. In the cerebellum, C3aR stimulation through subdural agonist delivery results in a transiently reduced thickness of the external granule cell layer (EGCL) and increased thickness of the internal granule cell layer (IGCL). Stimulation of C5aR results in the opposite phenotype. C3 and C5 may thus have opposing roles regulating cerebellar granule cell proliferation and migration $[16,17]$. Interestingly, there are no long-term gross cerebellar abnormalities in mice constitutively lacking C3, C5, C3aR, or C5aR [17] suggesting that these molecules may ensure proper cerebellar development by acting as a rescue mechanism in the event of developmental inflammation.

C3 also has demonstrated roles in synaptogenesis and synaptic plasticity. Motoneurons from C3 knockout mice have delayed clearance of synaptic terminals after axotomy, suggesting a C3 role in synapse maintenance [18]. C3aR null mice similarly expressed decreased GAP43 (a marker of synaptic 
sprouting), while C3aR overexpressing mice expressed increased GAP43 in a cortical stroke model [19]. C3 has been shown to mark or opsonize synapses for targeted pruning by microglia in the developing brain [20,9]; C3KO or loss of C3aR impairs synapse elimination in the thalamic lateral geniculate nucleus leading to non-segregated eye-specific territories and retention of multi-innervated relay neurons $[9,21]$. In mature synapses, C3 loss also lowers glutamate release probability in hippocampal CA3 and CA1 synapses without changing synaptic efficiency [22]. C3a can protect neurons from $\mathrm{N}$-methyl-D-aspartate (NMDA) induced injury; however, a direct mechanism has yet to be determined [23]. C3 knockout also protected mice from age related deficits in hippocampal function by preventing age-related decreases in hippocampal synaptic density, age-related decreases in hippocampal long-term potentiation, and agerelated neuron loss in CA3 [24]. These synaptic effects of C3 may have a significant role in early Alzheimer's disease pathology [25].

The above developmental and synaptic consequences of altered C3 function evoke distinct mouse behavioral phenotypes. Specifically, C3 knockout mice (strain C3 ${ }^{\mathrm{tm} 1 \mathrm{Crr}} / \mathrm{J}$ ) demonstrated enhanced spatial learning and altered working memory in a T-maze cognitive assay, as well as enhanced contextual

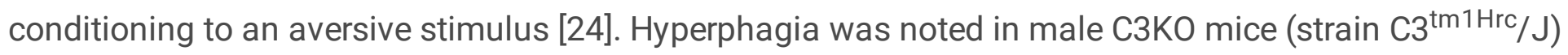
and quite prominent in female C3KO mice receiving a high fat diet $[26,27]$. C3KO mice (strain $\mathrm{B} 6 \mathrm{~N}(\mathrm{Cg})$ -

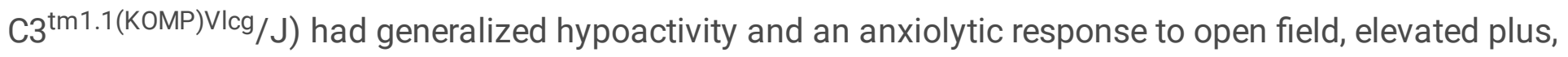
and novel object assays of exploratory behavior [24].

Our prior work has demonstrated that C3 expression increases with age in the cerebellum and hypothalamus of mouse strains with locomotor and metabolic phenotypes, respectively [28]. Similar ageassociated increases in $\mathrm{C} 3$ expression were noted in human cerebellar tissue [28]. To better understand how altered C3 expression may underlie these aging phenotypes, we used a constitutive C3 knockout mouse model to examine home cage behavior and metabolic status. These studies demonstrated that C3KO mice had decreased gait speed, increased gait ataxia, and altered active state movement probabilities compared to WT mice. Examination of forelimb strength and tibial plateau cortical bone anatomy and thickness further localized these gait disturbances to CNS, rather than biomechanical, causes. We finally demonstrated altered in vitro cerebellar granule cell properties in C3KO mice compared to WT.

\section{Methods}

\section{Mice and animal husbandry}

Cohorts of 2 month old male C57BL6/J ( $n=8$; stock \#000664) and B6;129S4-C3 ${ }^{\text {tm1Crr }} / \mathrm{J}$ (C3KO, stock \#003641) mice were acquired from The Jackson Laboratory (Bar Harbor, ME) for behavioral testing, synapse studies, and breeding. Of note, genotyping (per JAX) revealed that this strain had 3 markers (one each on chromosomes 7, 12, and 19) that were not fixed for C57BL/ 6 alleles; with the chromosome 12 marker indicating $129 \mathrm{~S} 4$ allele homozygosity. This finding suggests that C3KO mice employed in this study were not fully congenic to the control C57BL/ 6 strain, but rather retained < 3.1\% 129S4 DNA. Pups 
for in vitro synapse studies were generated using a triad mating system matching two C57BL/ 6 females to one C57BL/ 6 male to breed pups yielding WT cerebellar internal granule cells. Similarly, we matched two C3KO females to one C3KO male to breed pups yielding cerebellar internal granule cells with constitutive C3 loss.

C3KO mice were generated by homologous recombination of a PGK-neomycin cassette into a C3 exon coding for the $\mathrm{C}$-terminal region of the beta chain and the $\mathrm{N}$-terminal region of the alpha chain [29]. This site is required for processing pro-C3. Previous studies have shown that these C3KO mice have a disrupted C3 genomic locus [29], loss of C3 protein product by Western blot [24], absent immunostaining for C3 protein product in the kidneys and brain [30, 9], and loss of C3 mRNA signal from hepatic-derived samples [31, 32]. No serum C3 functional activity was detected in homozygous mutant mice. To reduce delivery-associated stress, mice were acclimated to the UNMC vivarium for 1-2 weeks prior to behavioral assessment. During this acclimation period, mice were singly housed in standard mouse cages on microisolator racks (Lab Products Inc., Seaford DE). Cages contained a layer of ground corn bedding (\#7097, Envigo, Huntington UK), and mice were provided with a nestlet (Ancare, Bellmore NY), environmental enrichment (EnviroPak ${ }^{\circledR}$, WF Fisher Somerville NJ) and ad libitum access to chow (\#7012, Envigo) and water.

All studies were performed under regulatory supervision of the UNMC Institutional Animal Care and Use Committee (IACUC) with strict adherence to appropriate state and federal law (NIH Guide for Care and Use of Laboratory Animals).

\section{Home cage monitoring system}

The home cage monitoring system (HCM) was designed to characterize freely behaving mice with minimal human contact over an extended time period with high spatial and temporal resolution. Characterization of this system has been reported [33,34]. A major strength of this system is that it provides highly replicable data (both within- and across institution and investigator) demonstrating strainspecific circadian activity, feeding, and drinking patterns. To assess activity, the system measures torque at three load cells positioned in a triangle at the base of the cage. Mouse coordinates are determined by solving exact equations relating torque, force, and moment arm length. Load cell voltages are sampled at $1 \mathrm{KHz}$ permitting temporal resolution of $1 \mathrm{~ms}$. Chow consumption is determined by measuring photobeam breaks as the mouse accesses a special cage chamber for food; water consumption is determined by a capacitive lickometer attached to the sipper tube.

Raw data undergoes automated quality control to identify events that may impact data reliability (blocked photobeam, leaking lick spout, excessive position drifts). If identified, these data are removed from further analysis. Data loss from these errors is typically much less than $1 \%$ of total collected data. Quality-controlled data then undergoes automated classification to determine mouse patterns of wakefulness and sleep (active/inactive states), and to classify ingestive and motor behaviors. These algorithms are described in detail in supplemental methods [33]. 
Locomotor bouts and movement-in-place bouts are determined using a machine learning algorithm that examines gait speed and turning angle characteristics of all locomotor events not involving either the feeder or licker, and uses the distribution of these measures to determine if movements best conform to forward locomotion, movement in place, or no movement. Data from all locomotor states can then be further analyzed for bout duration and onset timing of each event. We measured gait ataxia using minimum bounding rectangle (MBR) analysis to quantify the straightness of individual locomotor paths [35].

Following acclimation to the UNMC facility, mice ( $n=8 \mathrm{WT}, n=8 \mathrm{C} 3 \mathrm{KO})$ were moved into the home-cage monitoring system for a total of 21 days. Within the $\mathrm{HCM}$, each mouse was housed in a low profile cage (Allentown PC10196HT, $48 \times 26 \times 15 \mathrm{~cm}^{3}$ ). Within each cage were a nestlet, niche, corn bedding, and Alpha-dri Plus ${ }^{\circledR}$ tabs (Shepherd Specialty Papers, Watertown, TN) to reduce ammonia levels. Each cage contained an aluminum niche with dimensions similar to wild mouse burrows; the niche is intended to bias mouse sleeping behavior to a specific location within the cage. While in the HCM mice had ad libitum access to milled chow (\#5058 PicoLab) and water. The health of each animal, as well as the level of food and water available was visually checked daily. Food and water were changed twice weekly, and the entering and exit weights used to estimate daily food and water consumption. Mice were habituated to the system over the first five testing days; this habituation period was not analyzed. The last 16 days of data collection were analyzed for genotypic differences in home cage behavior.

\section{Metabolic Assays}

To test for differences in body composition or metabolic function, the same cohorts of WT and C3KO mice that underwent home cage monitoring assay were assessed using dual energy $\mathrm{X}$-ray absorptiometry (DEXA) and indirect calorimetry. We calibrated the DEXA system (PIXImus I scanner, and Piximus 2.10 software, Inside/Outside Inc., WI) with a vendor-supplied phantom, and measured body mass composition by standard protocol (modified from mutant mouse phenotyping center www.mmpc.org/shared/showFile.aspx?doctypeid=3\&docid=104 and Whitelabs www.whitelabs.org/Lab\%20Protocols/live\%20animal\%20protocols/DEXA\%20scanning\%20protocol.htm). We focused our assessment on central adiposity, and chose the abdomen just below the diaphragm as our region of interest (ROI). In this $\mathrm{ROI}$, we measured bone mineral density (BMD), bone mineral content $(B M C)$, bone area (BArea), tissue area (TArea), ratio of soft tissue attenuation $\left(R_{S T}\right)$, total tissue mass (TTM), and percent adiposity. We obtained body weight using a digital scale (Scout Pro SP401, Ohaus, Parsippany NJ).

Indirect calorimetry was performed using an open circuit system (Oxymax Equal Flow, Columbus Instruments, $\mathrm{OH}$ ) composed of an air pump, $\mathrm{CO}_{2}$ sensor (range $0 \%-0.8 \% ; 0.002 \%$ resolution; drift < 20ppm $\mathrm{CO}_{2}$ per hour), paramagnetic $\mathrm{O}_{2}$ sensor (range $0-100 \% ; 0.002 \%$ of specified range resolution; drift $<0.06 \%$ of specified range per 24 hours), air dryer, controller, 8 hermetically sealed indirect calorimetry chambers $\left(2.1 \times 10.2 \times 12.7 \mathrm{~cm}^{3}, \# 760 \mathrm{M}-\mathrm{D} 8\right.$, Columbus Instruments), chamber photocell bracket $(1.27 \mathrm{~cm}$ spacing between photocells), photocell controller (Opto M3, Columbus Instruments), and Oxymax for Windows 
4.49 running on dedicated hardware. Mice were fasted from roughly 5:00 PM until testing at 11:00 AM. Prior to running indirect calorimetry the system was calibrated. Calibration gases consisted of $100 \% \mathrm{~N}_{2}$ and a mixture of $0.5 \% \mathrm{CO}_{2} / 20 \% \mathrm{O}_{2} / 79.5 \% \mathrm{~N}_{2}$ (span gas). Indirect calorimetry assessments for each mouse were taken 20 times, each assessment over a continuous 2 minute epoch. Therefore, 40 minutes of data was collected for each mouse over a period of roughly 5.5 hours. We obtained the following outcomes: maximum oxygen uptake $\left(\mathrm{V}_{2}\right)$, input vs. output oxygen difference $\left(\mathrm{DO}_{2}\right)$, output oxygen concentration $\left(\mathrm{O}_{2}\right.$-out), maximum carbon dioxide production $\left(\mathrm{V}_{\mathrm{CO}}\right)$, input vs. output carbon dioxide difference $\left(\mathrm{DCO}_{2}\right)$, output carbon dioxide concentration $\left(\mathrm{CO}_{2}\right.$-out), and generated heat (calculated by Oxymax per User Manual version 0233-118M, Eq. 13, p. 72). Basal metabolic rates were calculated by averaging values from three epochs where the individual mouse demonstrated the least activity (as determined by a photobeam bracket spanning the longest chamber dimension). Activity-associated metabolic rates were calculated by averaging values from the three epochs where the mouse had the most activity.

Microtomography of the knee joint.

Power studies using microtomography data from prior studies to estimate sample means and variance suggested that we could detect a $15 \%$ difference in the bone volume to tissue volume (BV/TV) ratio at $\mathrm{a}=$ 0.05 and $\beta=0.20$ using a sample size of $n=5$ WT (98 days old) and $n=5$ C3KO ( 88 days old) mice. Mice of these cohort sizes were thus initially perfused with PBS until running clear (approx $3 \mathrm{~min}$ ) using automated perfusion system; then perfused with $4 \%$ paraformaldehyde for 5 minutes. Hindlimbs were disarticulated from the body at the hip joint, and immersed in $4 \%$ PFO for additional fixation. Hindlimbs remained in 4\% PFO for at least one month to ensure full fixation of the entire limb. C3KO and WT groups sacrificed at different times so mouse ages would be fully comparable.

Microtomography data of the knee joint was acquired using a Skyscan 1172 (Bruker) scanner and C9300 $11 \mathrm{Mp}$ camera (Hamamatsu). The samples were scanned under following parameters: $55 \mathrm{kV}$ voltage, 181 $\mu \mathrm{A}$ current, $785 \mathrm{~ms}$ exposure, $8.82 \mu \mathrm{m}$ resolution, $0.5 \mathrm{~mm}$ aluminum filter, $0.4^{\circ}$ rotation step, 4 frames averaging, 10 random movements, and $180^{\circ}$ rotation scanning.

The following workflow was employed to determine BV/TV, a parameter directly correlated with bone density. The software platform was 3D.Suite (Bruker) provided by the UNMC microCT core. We used NRecon 1.7.4.6 (Bruker) to make 3-D reconstructions of raw microtomography data with corrections (as necessary) for misalignment compensation, ring artifact reduction, dynamic range adjustment, and beam hardening adjustment. Tibia were oriented using DataViewer 1.5.6.2 (Bruker), and all samples were 3Dregistered. During registration, great care was taken to ensure as close a fit as possible in the coronal, horizontal, and sagittal planes. Following registration, the tibia was isolated using CTAn 1.18.8.0 (Bruker) with contoured region of interest. To determine our primary outcome, bone volume fraction (BV/TV, \%), we set the upper boundary for analysis along the plane where the femur and tibia articulate; we set the lower boundary 60 slices below the upper to maximize inclusion of cortical bone while minimizing inclusion of trabecular bone. Scanning data quality for one member of the WT cohort was inadequate for 3-D 
reconstruction using NRecon; this mouse was dropped from the study. Three-dimensional reconstruction of the knee joint to which all study data was registered was created by CTVox 3.3.0 (Bruker). Data quality for one WT and one C3KO mouse were inadequate for tibial plateau 3-D rendering, and were thus not included in the final figure.

\section{Mouse Grip Strength}

Power studies using grip strength data from prior studies to estimate sample means and variance suggested that we could detect a $50 \%$ difference in the grip strength at $\alpha=0.05$ and $\beta=0.20$ using a sample size of $n=5 \mathrm{WT}$ and $n=5$ C3KO mice. We used a single-sensor mouse grip strength meter (1027SM, Columbus Instruments) to measure mouse forelimb grip strength. Sensor range is $0-1 \mathrm{~kg}$ with accuracy within $0.25 \%$ of full scale reading. Testing parameters were in peak tension mode (recommended to test forelimb strength), with output unit set to Newtons. We calibrated the grip strength meter to zero force before data collection. Mice ( $n=5 \mathrm{WT}$, 98 days old; $n=5 \mathrm{C} 3 \mathrm{KO}$, 88 days old) were positioned to grip the triangle center with both forearms; gentle tension was then applied at the base of the mouse's tail until unable to maintain grip. Each mouse was assessed three times, with a 10 min intertrial interval between each effort.

\section{Primary Cerebellar Granule Cell Culture (pCGC)}

We used a pre-existing published protocol to culture cerebellar granule cells under nondepolarizing conditions [36]. To prepare cerebellar neuron cultures, post-natal mice (P4-P6) were rapidly decapitated, and the brain removed and placed into cold calcium-magnesium free PBS in a petri dish on ice. Brains were then transferred to a new petri dish with fresh ice cold PBS and the cerebellum removed under a dissecting microscope. The white matter in the center of the cerebellum containing the deep cerebellar nuclei was removed leaving predominately cerebellar folia with a small amount of white matter connecting them. Meninges were removed in strips by carefully pulling meningeal tissue laterally along the surface of the brain using fine dissection forceps. Cerebellar tissue was then transferred to a new petri dish with ice-cold PBS (Hyclone \#SH30256). This process was then repeated for additional brains with a maximum of 12 per procedure to minimize time from dissection to culture.

Once all brains were dissected, each was segmented into small relatively uniform (1-2 mm) pieces using micro dissection scissors under a dissecting microscope. Using a $25 \mathrm{~mL}$ pipette the tissue pieces were transferred to separate $15 \mathrm{~mL}$ conical tubes holding $10 \mathrm{~mL}$ of cold PBS. As a wash step dissected tissues were allowed to sink to the bottom of the conical tubes. PBS was then aspirated from the tubes and $1 \mathrm{~mL}$ of a trypsin solution ( $1200 \mu \mathrm{L}$ of $2.5 \%$ Trypsin (Worthington Labs \#3707), $33 \mu \mathrm{L} 30 \%$ glucose (Fisher \#D16)), and $1767 \mu \mathrm{L}$ of BME stock solution (240 mL Earls Balanced Salt Solution (EBSS), $2.5 \mathrm{~mL}$ Basal Medium Eagle vitamins (Sigma-Aldrich \#B6891), $2.5 \mathrm{~mL}$ Basal Medium Eagle amino acid solution (Sigma-Aldrich \#B6766), and $1 \mathrm{M} \mathrm{NaHCO}_{3}$ to $\mathrm{pH}$ of 7.2-7.4) was added. Tissue was incubated at room temperature in trypsin solution for 3 minutes with occasional manual mixing to evenly distribute tissues in solution. Following incubation, trypsin solution was removed and $1 \mathrm{~mL}$ of DNase solution $(150 \mu \mathrm{L}$ of 1\% DNase (Sigma \#DN25), $183 \mu \mathrm{L} \mathrm{30 \%} \mathrm{D-glucose,} \mathrm{and} 2817 \mu \mathrm{L}$ of BME stock solution) was added to 
degrade any DNA released from cells damaged during dissection. The addition of DNase solution aids in downstream trituration, as it reduces tissue clumping.

Using a P1000 pipette set to $750 \mu \mathrm{L}$ the tissue was triturated until a single cell suspension was formed (trituration maximum of 15 repetitions). The single cell suspension was then centrifuged at $700 \mathrm{G}$ for 5 minutes at $4^{\circ} \mathrm{C}$. The DNase solution was then removed and $2 \mathrm{~mL}$ of cold PBS with $500 \mu \mathrm{L}$ of DNase solution was added, followed by resuspension using a P1000 pipette as previously described. The single cell suspension in each tube was then filtered through a $40 \mu \mathrm{m}$ nylon cell strainer (BD Falcon \#352340) into new $15 \mathrm{~mL}$ conical tubes to remove any aggregated cells or tissue that failed to break down. After filtering, cells were pelleted by centrifugation at 700G for 5 minutes at $4^{\circ} \mathrm{C}$. The PBS/DNase solution was removed and the pellet re-suspended in $1 \mathrm{~mL}$ pre-warmed serum containing plating media $(81.5 \mathrm{~mL} \mathrm{BME}$ stock solution, $5 \mathrm{~mL}$ fetal bovine serum (Gibco \#10100-139), $2.5 \mathrm{~mL}$ horse serum (Sigma-Aldrich \#H1138), $50 \mu \mathrm{L}$ pen-strep solution (Gibco \#15140-122), $500 \mu \mathrm{L}$ L-glutamine (Gibco \#25030-081), $800 \mu \mathrm{l}$ $30 \%$ D-(+)-glucose (Sigma \#G8270), and $50 \mu \mathrm{L}$ of $1 \%$ DNAase solution). Cell density was quantified using a hemocytometer. Cells were plated at a density of 200,000 cells per $14 \mathrm{~mm}$ onto glass insert petri dishes (MatTek \#P35G-0-14-C) or 24 well plastic bottom dishes (BD Falcon \#351147). All plating surfaces were coated with $100 \mu \mathrm{M}$ poly-D-lysine (Sigma \#P7886 or \#P6407) for 4-6 hours before cell isolation and washed twice with sterile culture grade water (Hycone \#SH30529) before plating.

Cells were incubated for $4-6$ hours at $37^{\circ} \mathrm{C}$ and $5 \% \mathrm{CO}_{2}$ to facilitate adherence. Serum containing media was removed and each coverslip or petri dish was gently rinsed with pre-warmed serum free media (92.4 $\mathrm{mL}$ Low-Glucose DMEM (Life \#11965-092), 2 mL of N2 supplement (Gibco \#17502-048), 2 mL B27 supplement (Gibco \#17504-044), $1.6 \mu \mathrm{l}$ 20\% sucrose (Fisher \#BP22-01), $1 \mathrm{~mL}$ L-glutamine, and $100 \mu \mathrm{l}$ Pen-Strep). Fresh pre-warmed serum-free media $(2 \mathrm{~mL})$ was then added to each well. After two days in culture, $5 \mu \mathrm{M}$ AraC (Sigma \#C1768) was added to inhibit the growth of dividing cells, primarily glia and endothelia. One half of the media was replaced with fresh serum free media on day 4 and then every half of the media was changed every three days.

\section{pCGC culture transfection}

We transfected primary cerebellar granule cell cultures at DIV2 using lipofectamine 2000 (ThermoFisher \#11668027) with $1.0 \mu \mathrm{g}$ of a plasmid with green fluorescent protein (GFP) expression under control of a CMV promoter (courtesy of Arikkath lab, [37]) using manufacturer's recommended protocol. In the first tube we combined plasmid DNA with DMEM (Life \#11965-092) at the above concentrations to reach 25 $\mu \mathrm{L}$ per well. In the second tube, we combined $2 \mu \mathrm{L}$ lipofectamine with $23 \mu \mathrm{L}$ per well of DMEM. The tubes were mixed, incubated at room temperature for 15 minutes, and $50 \mu \mathrm{L}$ of the mixture added to each well. With this method we achieved low-density transfection suitable for analysis of individual cerebellar granule cell synaptic densities.

\section{Immunocytochemistry}

Primary cerebellar neuron cultures were fixed with $4 \%$ paraformaldehyde/4\% sucrose solution pre-warmed to $37^{\circ} \mathrm{C}$ for 10 minutes at room temperature. Cultures were rinsed 3 times in PBS (Hyclone). To allow 
antibody access to intracellular protein epitopes, cells were permeabilized with $0.1 \%$ triton X-100 for 10 minutes at room temperature. Following permeabilization cells were rinsed 3 times for 10 minutes in PBS then blocked with 5\% BSA in PBS for 1 hour at room temperature. After blocking, primary antibodies were diluted in $1 \%$ BSA in PBS and incubated overnight at $4^{\circ} \mathrm{C}$. Primary antibodies used in this study were against NeuN (anti-mouse, Millipore, \#MAB377, 1:100), GFAP (anti-chicken, Neuromics, \#CH22102, 1:2000), CD11b (anti-rat, Abcam, \#ab8878, 1:300), cleaved caspase 3 (anti-rabbit, Cell Signaling Technology, \#9661, 1:400), Vglut1 (anti-guinea pig, Millipore, \#AB5905, 1:4000), Vglut2 (anti-guinea pig, Millipore, \#AB2251, 1:4000), Gad65 (anti-mouse, Developmental Studies Hybridoma Bank, \#GAD-6, 1:100), and Vgat (anti-mouse, Synaptic Systems, \#131-011, 1:500). After primary incubation cells were rinsed 3 times in PBS, and incubated with appropriate secondary antibodies diluted in 1\% BSA in PBS for 1 hour at room temperature. All secondary antibodies were from the Alexa Fluor series (ThermoFisher) and used at 1:250-1:500. Cells were then washed 3 times with PBS for 10 minutes each. Nuclear counterstaining was completed with 4',6-diamidino-2-phenylindole (DAPI) in PBS for 1 minute. Cells were rinsed twice with PBS and then cover slipped using Prolong Gold or Diamond Antifade Reagent (Invitrogen P36934 or P36961). Mounting media was allowed to dry overnight in the dark and then samples were stored at $-20^{\circ} \mathrm{C}$ or $-80^{\circ} \mathrm{C}$ until imaging.

\section{Confocal Imaging of pCGC Cultures}

Synaptic densities, cell types, and caspase-3 activation in PCGC cultures were all analyzed using confocal microscopy under blinded conditions. All images were collected using a Zeiss LSM 700 scanning confocal microscope with either 10x (Zeiss EC Pan-Neofluar 10x/0.3 NA, $1.11 \mu \mathrm{m}$ resolution, \#4403309902-000), 20x (Zeiss EC Plan-Neofluar 20x/0.50 NA, $0.67 \mu \mathrm{m}$ resolution, \#420350-9900-000), or 40x (Zeiss EC Plan-Apochromat 40x/1.3 NA, $0.26 \mu \mathrm{m}$ resolution, \#420762-9800-799) objectives. All data was collected using settings optimized for each experiment and the settings were maintained across all samples. Confocal imaging was restricted to a maximum of 4 channels using $405 \mathrm{~nm}(5 \mathrm{~mW}), 488 \mathrm{~nm}$ $(10 \mathrm{~mW}), 555 \mathrm{~nm}(10 \mathrm{~mW})$, and $639 \mathrm{~nm}(5 \mathrm{~mW})$ diode lasers, with each set to collect on independent channel for minimal bleedthrough. For pCGC culture cell type analysis, images were collected using the $20 x$ objective with $0.5 x$ digital zoom to increase the field of view. For in vitro synaptic density analysis, $z$ stack images were taken using a 40x objective at $1024 \times 1024$ resolution $(160 \mu \mathrm{m} \times 160 \mu \mathrm{m} \times 4.58 \mu \mathrm{m}$; $0.352 \mu \mathrm{m} z$-step). For cell type and cleaved caspase- 3 measurements images were collected using a $20 \mathrm{x}$ objective with $0.5 x$ digital zoom at $1024 \times 1024$ resolution $(640 \mu \mathrm{m} \times 640 \mu \mathrm{m})$ with focus set to the brightest DAPI plane.

\section{Analysis of Cell Types and Apoptosis}

To determine the relative distribution of cell types in the cultured cell population, pCGC cultures were fixed and immunostained for markers of neurons (NeuN), astrocytes (GFAP), and microglia (CD11b) at DIV6. Images were collected by confocal microscopy and analyzed using analyze particles feature in ImageJ software [38]. A minimum of 8 fields (technical replicates) per sample were imaged across multiple experimental (biological) replicates ( $n=3$ for C3KO, $n=2$ for WT as well as prior pCGC validation studies). Images were uploaded as .Ism files and the global scale was set based on imaging parameters. For the 
$\mathrm{DAPI}^{+}$and $\mathrm{NeuN}^{+}$cell quantification, a macro was used to automate the counting procedure. First, the batch threshold was set manually where fainter cells were quantifiable while the brighter cells remained distinct from surrounding cells. Images were then smoothed to ensure detection of cell borders and converted to binary, where the watershed function was used to separate closely opposed cells. Cells were quantified using the 'analyze particles' function controlling for size and circularity. To validate count accuracy, the masks feature was used and overlaid on the original image. For quantification of nonnuclear GFAP and CD11b immunoreactivity, the positive cells were counted manually using the cell counter application of ImageJ.

Cell type analysis for C3KO and WT pCGC cultures was performed using the detect spots feature in IMARIS (Bitplane, South Windsor CT) controlling for fluorescent signal intensity and quality.

\section{Analysis of pCGC Synaptic Density}

Gross synaptic densities were quantified in blinded samples using detect spots function in IMARIS software on blinded confocal images. Settings for puncta size and quality were optimized for the data set and remained uniform for all samples. Vglut1 and GAD65 puncta counts were quantified, along with the number of DAPI positive cells per field. Data was presented as gross synaptic counts per field, as well as counts normalized to the number of cells per field. To determine cell specific synaptic densities per $\mu \mathrm{m}^{2}$ of surface area, pCGC transfected with GFP were imaged and analyzed. Using the create surfaces function in IMARIS the structure of the cell was generated. Next, detect spots was used to identify excitatory and inhibitory synaptic puncta. We then used the split into surface objects function to identify synaptic puncta in contact with the generated surface. The number of puncta detected was then normalized to surface area of the individual cell.

\section{RNA isolation, purification, and RT-PCR}

RNA was isolated from primary cerebellar granule cell cultures generated from WT and C3KO mice using a RNeasy Minikit (Qiagen \#74104). Briefly, the media from DIV6 cultures was removed and the cells were rinsed with sterile PBS. RLT buffer was then added and repeatedly rinsed over the surface of the well to ensure even cell disruption. Buffer was then collected from individual wells and further disrupted with a tuberculin syringe 5-7 times in a $1.5 \mathrm{~mL}$ conical tube. The remainder of the RNA isolation was as described in manufacturer protocol.

RNA purity was assessed using spectrophotometry (NanoDrop II, Thermo, Waltham MA) to measure $\AA 260 / 230$ and $\AA 260 / 280$ ratios. RNA degradation was assessed by micro gel electrophoresis (BioAnalyzer 2100, Agilent Technologies). Only RNA samples meeting minimum purity and quality were used for downstream analysis. Specifically, any samples with $\AA 260 / 280$ ratios less than 1.8 were deemed unsuitable for analysis secondary to RNA contamination. Additionally, any samples with larger $18 \mathrm{~S}$ instead of $28 \mathrm{~S}$ peaks, or RNA integrity numbers (RINs) $<7.0$ were deemed unsuitable for analysis secondary to RNA degradation. 
RT-PCR was performed using Verso SYBR Green 1-Step kits (Thermo Scientific \#AB4105) according to manufacturer protocols. All primers used were from the QuantiTect Primer Assay series (Qiagen). All samples were run in triplicate and each reaction contained both no template and no primer controls. A full melt curve was generated for each reaction to ensure a solitary product. RT-PCR data was analyzed for relative expression using the $2^{(-\Delta \Delta C T)}$ method with normalization to Gusb as a housekeeping gene using Microsoft Excel.

\section{Calcium Imaging and Analysis}

To assess functional properties of cerebellar granule cells generated from WT and C3KO mice, we performed live cell calcium imaging using Fluo-4AM, a calcium indicator dye that is permeable to cell membranes (ThermoFisher \#F14201). Since Fluo-4AM fluorescence magnitude in response to $\mathrm{Ca}^{++}$ depends upon many factors, including solution temperature, $\mathrm{pH}$, ionic strength, and pressure, these results provide qualitative, but not strictly quantitative, differences in $\mathrm{Ca}^{++}$response between neurons from WT and C3KO mice [39]. pCGC cultures were loaded with $1 \mu \mathrm{M}$ Fluo-4AM and pluritonic acid for stabilization and imaged using an upright fluorescent microscope. Cultures were imaged in artificial cerebrospinal fluid (mM: $124 \mathrm{NaCl}, 26 \mathrm{NaHCO}_{3}, 3 \mathrm{KCl}, 2 \mathrm{MgCl}_{2}, 2 \mathrm{CaCl}_{2}, 1.25 \mathrm{NaH}_{2} \mathrm{PO}_{4}, 10$ glucose, 0.5 ascorbic acid, $1.5 \mathrm{Na}$-pyruvate, 1 thiourea; $\mathrm{pH} 7.4$, maintained by carbogen [95\% $\mathrm{O}_{2}$ and $5 \% \mathrm{CO}_{2}$ ] bubbling at room temperature). pCGC cultures were imaged every 5 seconds, Neuronal depolarization was induced after 1 minute (cycle 15) by adding $25 \mathrm{mM} \mathrm{KCl}$ to the aCSF. Images were analyzed using Axiovision Software (version 4.8.2.0, Zeiss). A total of 60 WT cells and 90 C3KO cells were analyzed from samples generated from 2 and 3 biological replicates respectively. A third WT sample was lost due to complications with imaging autofocus parameters. For analysis, baseline fluorescent intensity for each cell was calculated as the average GFP intensity of the first minute of imaging (a total of 12 cycles with 5 seconds between cycles). The GFP intensity of each cell at each time point was then normalized to individual cell baseline to generate a fold change from baseline.

\section{Transcardial Perfusion and Tissue Processing}

WT or C3KO male mice at 1 and 3 months of age were deeply anesthetized with $17 \mu \mathrm{l} / \mathrm{g}$ body weight of 2.5\% Avertin (2,2,2-Tribromoethanol 97\%, Sigma \#T48402). Transcardial perfusion was performed to preserve tissue architecture for downstream histological analysis. Mice were perfused by perfusion pump (Manostat ${ }^{\circledR}$ Vera, Sigma) with PBS for 3 minutes to clear blood, followed by 5 minutes with 4\% PFA/PBS (32\% Paraformaldehyde Stock, Electron Microscopy Sciences, \#15714). Following perfusion, the brain was collected and post fixed in $4 \%$ PFA/PBS for 24 hours at $4^{\circ} \mathrm{C}$. To preserve cell architecture and prevent crystal formation upon freezing, brains were cyroprotected with $30 \%$ sucrose at $4^{\circ} \mathrm{C}$ until the tissues sank, roughly 24 hours. Tissues were then embedded in Sakura ${ }^{\circledR}$ Tissue-Tek ${ }^{\circledR}$ OCT. (VWR, \#4583), and frozen in dry ice and ethanol slurry. Tissue blocks were stored at $-80^{\circ} \mathrm{C}$ for further processing. For sectioning, OCT tissue blocks were allowed to equilibrate to the cryostat temperature of $-20^{\circ} \mathrm{C}$ for 30 minutes.

Tissues were sectioned on a cryostat (Leica Cyrostar NX50) in either the sagittal or coronal plane at 14 $\mu \mathrm{m}$ and directly mounted on glass slides (Fisher Scientific, \#12-550-15). Tissues mounted on slides were stored at $-80^{\circ} \mathrm{C}$ until staining. 


\section{Immunohistochemistry}

To assess for genotypic differences between wildtype and C3KO mice in vivo, tissue sections were immunostained with antibodies targeting specific synaptic proteins. We used the same antibodies at the same dilutions employed for cell culture immunocytochemistry as discussed above. Tissue sections were warmed to room temperature for 30 minutes prior to processing. Slides were washed 3 times in PBS to remove excess OCT, followed by blocking in $5 \%$ bovine serum albumin (BSA) in PBS. To promote antibody access to intracellular epitopes, the blocking, primary, and secondary antibody buffers contained $0.2 \%$ Triton-X 100 . After blocking, slides were incubated overnight at $4{ }^{\circ} \mathrm{C}$ in antibody solution $(0.5 \% \mathrm{BSA}$ in PBS with $0.2 \%$ Triton) containing primary antibodies for excitatory and inhibitory synaptic proteins. Following overnight incubation, slides were washed 3 times in PBS. The slides were then covered with antibody solution containing species-specific secondary antibodies for 2 hours at room temperature in the dark. Following secondary antibody staining, slides were washed 3 times, counterstained with DAPI, washed again, and cover slipped with Prolong Diamond anti-fade mounting media. Slides were dried overnight in the dark at room temperature and then stored at $-20^{\circ} \mathrm{C}$ until imaging.

\section{In Vivo Synaptic Density Confocal Microscopy}

Densities of excitatory (Vglut1, Vglut2) and inhibitory (GAD65) synaptic proteins in wildtype and C3KO mice were assessed using confocal microscopy. To assess synaptic density in the molecular layer, confocal z-stack images from 3 month old mice were acquired using 40x objective and 2x zoom on a Zeiss LSM 700 scanning confocal microscope. Images were taken at $1024 \times 1024$ resolution over a 160 $\mu \mathrm{m} \times 160 \mu \mathrm{m} \times 12.04 \mu \mathrm{m}$ window with a z-step of $0.430 \mu \mathrm{m}$. Synaptic formations in the cerebellar granule cell layer were imaged under the same objective and settings, but with modified gain and laser intensity.

\section{Analysis of In Vivo Synaptic Density}

The primary vesicular protein associated with molecular layer excitatory synapses is Vglut1 arising from parallel fibers of cerebellar granule cells. Vglut1 puncta in the molecular layer are very dense and uniform in size. To detect each puncta, we employed the detect spots feature in IMARIS software controlling for fluorescent signal quality. GAD65 positive and Vglut2 positive puncta were assessed using the same feature but were less uniform in size. We also quantified average puncta volume using the 'Detect spots of varying sizes' feature with local contrast settings to define sizes. Output from this analysis included the number of puncta, average puncta mean intensity, average puncta median intensity, and for Vglut2 and GAD 65 the average puncta volume.

Input to cerebellar granule cells occurs through a specialized glomerular synaptic structure. Thus, individual synaptic puncta are not well defined. For quantifying Vglut1 and Vglut2 in the cerebellar granule cell layer, the 'Create surfaces' function was used to map the structure of the excitatory synaptic glomerulus. GAD65 puncta, which form an inhibitory ring around each glomerulus, were identified using the 'Detect spots' feature. The output for this analysis included the number of glomeruli, average 
glomerulus surface area and volume, fluorescent intensity mean and median of glomeruli, and the number, size and intensity of GAD65 puncta.

\section{Statistics}

Home cage assay. To control familywise-error rates, we first perform false discovery rate analysis (FDR; [40]) across all 665 behavioral measures assessed by the system. Behavioral categories (e.g. overall measures, behavioral time budgets, active/inactive state properties, ingestion bout properties, movement bout properties, peri-event active state properties) containing one or more differentially-expressed behaviors are then examined in more detail to elicit patterns. Specifically, we employ two-way ANOVA to assess for behavioral differences (genotype and light/dark cycle as treatment), and perform Tukey's posthoc test and Bonferroni correction for multiple comparisons as required.

Minimum bounding rectangle. Differences in MBRs were quantified by repeated measures ANOVA using genotype as treatment factor, replicated for each animal over all days of data collection, and individual mice as covariates.

Dual emission X-ray absorptiometry. We employed Bonferroni-corrected two-tailed t-tests to test for differences in DEXA parameters.

Indirect calorimetry. ANCOVA analysis was performed to identify significant differences in metabolic parameters $\left(\mathrm{VO}_{2}, \mathrm{DO}_{2}, \mathrm{O}_{2}\right.$-out, $\mathrm{VCO}_{2}, \mathrm{DCO}_{2}, \mathrm{CO}_{2}$-out, and heat) between genotypes as a function of adiposity and lean-body mass [41].

Microtomography of the knee joint. We employed one-way analysis of variance (ANOVA, implemented by anova1 function in MATLAB R2019a) with BV/TV as response and genotype as treatment to determine if genotype had any effect on cortical bone density.

Mouse grip strength. Data was analyzed by repeated measures analysis of variance (ANOVA, implemented by ranova function in MATLAB R2019a), with grip strength as response variable, genotype as predictor variable, replication as within-subject variable, and Greenhouse-Geisser adjustment for lackof-sphericity.

Analysis of cell types and apoptosis. Statistics for activated caspase-3 staining was performed in Microsoft Excel 2010, using a two-tailed student t-test to compare genotypes. Statistics were not performed on cell type analysis, as we only used 2 biological replicates for WT controls. However, the data concurs with that generated for original culture characterization.

Analysis of pCGC synaptic density. All comparisons were performed using two-tailed student t-tests in Microsoft Excel 2010. Pilot experiments were performed on DIV5 cultures to determine mean and variance characteristics for excitatory and inhibitory puncta in WT and C3KO primary cerebellar cultures; using these values in a standard experiment power calculator revealed that we could detect a $10 \%$ or 
greater difference between these two means ( $a=0.01$ and $b=0.8$ ) by examining 95 internal granule cells per genotype (excitatory puncta) or 148 internal granule cells per genotype (inhibitory puncta).

Calcium imaging and analysis. Fold change data was analyzed by two-way repeated measures ANOVA controlling for genotype, time, and sample (SPSS Ver 22).

Analysis of in vivo synaptic density. Genotypic differences in glomeruli metrics were assessed by twosided t-tests assuming equal variance as implemented in Microsoft Excel 2010.

\section{Results}

\section{Decreased gait speed, increased locomotor bout duration with C3 loss}

We identified 143 behaviors differentially expressed by FDR between WT and C3KO mice. Differences were observed in aggregate measures of intake and movement, behavioral time budget, active state properties, ingestive bouts, and movement bouts. Volcano plots were generated from differential behaviors lists depicting significance versus fold change from WT. This analysis yielded 53 behaviors with a 2-fold or greater change from controls (Fig. 1). Of the 53 behaviors, 25 were significantly decreased and 28 significantly increased. Within this data set are several behavioral differences that correspond to functional aspects of locomotion, bout probabilities, and feeding and drinking properties.

There were no genotypic differences in overall locomotor movement $(\mathrm{cm} / \mathrm{hr})$ over the light cycle, dark cycle, or full circadian day (Fig. 2A). We found no genotypic differences in the number of locomotor bout onsets per hour or in bout probability (Fig. 2B,C). However, C3KO mice show a marked increase in locomotor bout duration across the circadian day (WT 786.35 $\pm 263.1 \mathrm{~ms}$, C3KO 1305.5 $\pm 370.8 \mathrm{~ms}$, FDR t-test $p=0.0192)$. This difference holds when the light cycle and dark cycle are assessed independently as well (Fig. 2D). Increased bout duration is likely a result of a significantly reduced forward locomotion gait speed in C3KO mice (WT $23.73 \pm 4.50$, C3KO $15.43 \pm 3.04 \mathrm{~cm} / \mathrm{s}$, FDR t-test $p=0.0067$; Fig. 2E). This difference holds though both dark and light cycles as well as the full circadian day. The changes in C3KO locomotor gait speed and bout duration tended to balance one another out, leading to no significant differences in per bout movement between WT and C3KO mice (Fig. 2F). These data collectively demonstrate that C3KO mice have deficits in functional aspects of locomotion, but motivation for locomotor appears to be spared, as the number of onsets, probability, and total movement are equal to controls. We observed concordant findings regarding mouse movement-in-place, defined as movements with low gait speed and high turning angles (Supplemental Fig. 1). Briefly, C3KO mice again displayed decreased movement-in-place bout speed, with no differences in movement-in-place bout onsets or probability. In contrast to forward locomotion, C3KO mice had similar length movement-in-place bout durations, and thus demonstrated less per-bout movement, and ultimately less overall movement.

Increased active state movement probability with C3 loss 
Of note, overall active state organization significantly differs between WT and C3KO mice with regards to locomotor behavior. We observe that, except for the first few minutes at the start of each active state, C3KO mice are more likely to engage in locomotion compared to WT mice. To demonstrate this finding, we first display the structure of every active state observed in the experiment (truncated to $180 \mathrm{~min}$ duration) for a representative WT and C3KO mouse (Fig. 3). In this manner, we can show the structure of every active state (up to $180 \mathrm{~min}$ ) that the mouse expressed. As one can observe, the representative C3KO mouse demonstrated more movement events (corresponding to green rasters) compared to WT. The inset extends this finding across the entire tested cohort, demonstrating that throughout the active state, C3KO mice were more likely to engage in locomotion compared to WTs $(p<0.006$, critical $p=0.0125)$.

\section{Increased gait ataxia with C3 loss}

To quantify potential gait differences between WT and C3KO cohorts, we measured locomotor path straightness using minimum bounding box areas fit to motor paths, a reliable approach to assess gait ataxia. Analysis of locomotor paths in WT and C3KO mice revealed a significant increase in median bounding box area in C3KO mice (median minimum bounding box area: WT $3.65 \mathrm{~cm}^{2}, \mathrm{C} 3 \mathrm{KO} 7.91 \mathrm{~cm}^{2}, p$ $<<1 \times 10^{-6}$ ), which is indicative of less straight locomotor paths (Fig. 4). Young C3KO mice thus demonstrate significantly more locomotor ataxia compared to age-matched WT controls.

\section{Loss of C3 does not impair metabolism or lead to significant changes in body composition}

We found minimal genotypic differences in body mass composition. There were no significant differences in BMD, BMC, total bone area, $\mathrm{R}_{\mathrm{ST}}$, adiposity, TTM, or body weight; a minimal difference was appreciated in TTA (WT $8.45 \pm 0.48$, C3KO $90.5 \pm 0.60, p=0.044$; Supplemental Fig. 2). Similarly, loss of C3 had no effect on either basal (Supplemental Fig. 3A) or activity-associated (Supplemental Fig. 3B) metabolic rates when normalized for adiposity. These results suggest that loss of $\mathrm{C} 3$ leads to minimal changes in metabolic properties or energy balance phenotypes on a C57BL/ 6 background.

\section{Loss of C3 does not affect forearm grip strength, tibial plateau articular surface morphology, or density of cortical bone at the tibial plateau}

Both muscle weakness and joint arthritis may compromise biomechanical function underlying locomotion, and thus lead to slower gait speeds. To examine these possibilities, we tested muscle strength by performing grip strength tests, and we performed microtomography of the knee joint to examine the tibial articular structure for arthritic changes. We found no genotypic difference in forelimb grip strength between WT and C3KO mice (Fig. 5A, repeated measures ANOVA, $n=5$ WT, $n=5$ C3KO, with no differences noted in either average strength or changes in strength over the testing procedure, $F_{2,12}=$ $4.18, N S ; F_{2,12}=3.27$, NS for genotype and time, respectively). Examination of the tibial plateau articular surface in both WT and C3KO males reveals no erosions or deformities consistent with joint arthritis (Fig. 5B). Similarly, we noted no differences in cortical bone thickness at the tibial plateau between WT and C3KO mice (Fig. 5C; one way ANOVA, $n=4 \mathrm{WT}, n=5$ C3KO, genotype NS, $\mathrm{F}_{1,7}=2.12$ ). 


\section{Increased Vglut1 + synaptic puncta in C3KO cerebellar granule cell cultures}

Complement proteins have been shown to tag synapses for pruning by microglia in multiple brain regions. Loss of complement expression has been linked to increased synaptic density in the cortex and hippocampus, but less is known about this process in the cerebellum $[24,9,20]$. To assess for synaptic alterations in cerebellar granule cells, primary neuron cultures enriched for granule cells were isolated from postnatal day 5 mice and matured in culture. WT and C3KO granule cell cultures $(n=3$ biological replicates per genotype) were fixed at multiple stages of synaptic maturation and immunostained for excitatory and inhibitory synaptic proteins. Across early stages of synaptic development (day in vitro 3 ) there were no significant differences in total gross excitatory (WT $367 \pm 112$; C3KO $522 \pm 98$ Vglut $1^{+}$ puncta per field; $p=0.145$ ) or inhibitory (WT $27 \pm 17$; C3KO $40 \pm 1$ VGAT puncta per field, $p=0.257$, Fig. 6A) synaptic density. Concordantly, we further found no genotypic differences in excitatory (WT $7.2 \pm$ 1.5; C3KO 9.5 \pm 3.0 Vglut ${ }^{+}$puncta per field; $p=0.30$ ) or inhibitory (WT $0.49 \pm 0.21$; C3KO $0.76 \pm 0.22$ VGAT puncta per field, $p=0.19$, Fig. $6 \mathrm{~B}$ ) synaptic densities when normalized to $\mathrm{DAPI}^{+}$cells per field.

However, when cerebellar granule cell cultures were analyzed at a later stage in synaptic maturation (day in vitro 6$),$ C3KO cultures ( $\mathrm{n}=3$ biological replicates) showed increased excitatory and inhibitory synaptic densities compared to WT controls ( $n=3$ biological replicates). This increase in excitatory synapses was consistent across several methods of quantification and normalization. When assessed as total puncta per field, C3KO cerebellar granule cell cultures show a greater than two fold increase in excitatory synaptic puncta (WT $1090 \pm 373$; C3KO $3066 \pm 254 ; p=0.0016$; Fig. 7A,B). There was no significant difference in the number of cells per field, but to account for any difference in synaptic number due to variability in cell density, we normalized synaptic counts to cells per field as above. C3KO cerebellar granule cells still showed a significant increase in excitatory synaptic puncta (WT $23 \pm 5$; C3KO $46 \pm 7 ; p=0.0107$; Fig. 7C). To assess inhibitory synaptic density, VGAT + puncta per field were quantified and C3KO mice show an increase in inhibitory synaptic puncta (WT $179 \pm 89$; C3 KO 392 $\pm 8 ; p=0.0149 ;$ Fig. 7A,B). This difference falls just below significance when normalized to cell number per field (WT 3.72 \pm 1.2 ; C3KO $6.01 \pm 0.76 ; p$ $=0.052 ;$ Fig. $7 \mathrm{C}$ ).

\section{Increased Vglut1 + synaptic puncta in individual cultured C3KO cerebellar granule cells}

The above studies suggest that the overall cerebellar granule cell phenotype evoked by C3 functional loss was characterized by a temporal increase in the neuronal expression of Vglut1 and VGAT. These findings justified further effort to examine this phenotype at single granule cells. Cerebellar granule cell cultures were thus transfected with a GFP vector to identify individual granule cell neurons and processes. Cerebellar neuron cultures were then fixed and stained for excitatory and inhibitory synaptic markers at day 3 and 6 in vitro. Individual cell synaptic input was then analyzed per $100 \mu \mathrm{m}^{2}$ of GFP + cell surface area as described in the methods. Cultures analyzed at DIV3 $(n=3$ biological replicates examining at least 20 neurons per genotype) showed no differences in Vglut $1^{+}$or $\mathrm{VGAT}^{+}$puncta, total cell surface area per cell, or primary dendrite number (Supplemental Fig. 4). However, at DIV 6, C3KO granule cells showed a significant increase in Vglut1 + synaptic puncta (WT $2.75 \pm 0.49$; C3KO $5.42 \pm 0.78 ; p<0.0075$ ), an 
increased number of VGAT + puncta per $100 \mu \mathrm{m}^{2}$ of GFP + cell surface area (WT $0.51 \pm 0.159 ;$ C3KO 0.81 $\pm 0.088 ; p<0.047$; Fig. 8A-C), and a greater number of primary dendrites (WT $6.03 \pm 0.15$; C3KO $6.83 \pm$ $0.31, p<0.015$; Fig. 8D) compared to WT controls. Again, we examined at least 20 neurons arising from 3 biological replicates per genotype to obtain the above finding. No genotypic differences in total surface area per cell were noted in granule cell neurons from DIV6 culture.

Complement proteins and receptors have been previously described to regulate cell migration, proliferation, and apoptosis. To assess whether synaptic differences seen in C3KO compared to WT cultures were a result of differences in cell populations, inflammatory signaling, or changes in apoptosis we performed immunohistochemistry for cell specific markers ( $n=3$ per genotype) including neurons (NeuN), astrocytes (GFAP), and microglia (CD11b), as well as cleaved caspase 3. Importantly, loss of complement protein $\mathrm{C} 3$ does not lead to any significant changes in cell type distribution, cell apoptosis, or inflammatory signaling in cerebellar neuron cultures that may alter synaptic density (Supplemental Fig. 5). Levels of other transcripts relating to NF-KB signaling (IKB- $a, I L-\beta, p 105$, IKK-a, Syk, p65) were also assessed by immunohistochemistry with no expression differences noted (p105, IKK-a, Syk, p65 data not shown). Additionally, pCGC cultures are enriched for neurons, with low levels of glial cells. Taken together, our data suggests that synaptic alterations are a result of neuronal complement 3 loss and not a secondary effect from changes in cell distribution or glial response. Next, we wanted to determine if increased synaptic density led to any changes in PCGC function that may underlie locomotor deficits.

\section{Increased responsiveness to $\mathrm{KCl}$ induced depolarization is a functional outcome of $\mathrm{C} 3$ loss}

As presented above, mature granule cell neurons from C3KO mice demonstrate increased protein expression of both Vglut1 and VGAT. This finding suggests that cerebellar granule cells from mutant mice may demonstrate altered responses to excitatory stimuli. Measuring changes in intracellular calcium levels is one method to assess neuronal response to activity-inducing stimuli. Treatment of neurons with potassium chloride $(\mathrm{KCl})$ results in robust depolarization by increasing the extracellular potassium concentration, opening voltage-gated calcium channels and evoking rapid $\mathrm{Ca}^{2+}$ influx. Using a cell permeant calcium indicator dye (Fluo-4AM) that exhibits fluorescence upon calcium binding, we assessed neuronal response to $\mathrm{KCl}$ induced depolarization in control and C3KO pCGC cultures. Cerebellar granule cells isolated from C3KO mice have an increased responsiveness to $\mathrm{KCl}$ depolarization and delayed washout response, taking longer to return toward baseline fluorescence (Fig. 9). A significant genotype $x$ time interaction for GFP intensity was noted by two-way repeated measures ANOVA $\left(F_{1,89}=30.6, p<1 \mathrm{x}\right.$

$\left.10^{-6}\right)$. This data demonstrates potential functional differences between WT and C3KO cerebellar granule cells.

\section{Loss of complement protein C3 does not alter cerebellar synaptic density in vivo}

Prior studies have shown that complement protein loss may increase excitatory synaptic density in select CNS regions [24]. Furthermore, our in vitro analysis of matured cerebellar granule cells revealed significant genotypic differences in both excitatory and inhibitory synaptic densities between neurons 
with and without C3 function. We therefore hypothesized that C3KO mice may have altered synaptic densities within selected regions of the cerebellum that underlie locomotor deficits. To quantify in vivo synaptic densities, we processed 1- and 3-month old WT and C3KO mice for immunohistochemistry and subsequent confocal microscopy of the cerebellar molecular and internal granule cell layers. The molecular layer contains the primary synaptic output from cerebellar granule cells, where projecting parallel fibers synapse with the extensive dendritic trees of Purkinje cells. As we observed increased excitatory synaptic density in cultures, we hypothesized we would observe similar changes in the molecular layer. However, quantification of Vglut1 + excitatory synapses and GAD65 inhibitory synapses in the molecular layer yielded no significant differences in synaptic puncta number or mean intensity (Supplemental Fig. 6A-C). In addition to Vglut1 positive synapses from cerebellar granule cells, climbing fibers from the inferior olive form Vglut2 excitatory synapses in the molecular layer. Quantification of Vglut2 positive synapses also yielded no differences in density or intensity (Supplemental Fig. 7A-C). As we observed no differences in the molecular layer, we then assessed the internal granule cell layer. Mossy fibers from the pons form excitatory synapses with cerebellar granule cells in a specialized synaptic structure (glomerulus) surrounded by a ring of inhibitory synapses. Quantification of glomeruli number, intensity, and volume of Vglut1 positive glomeruli and the GAD65 inhibitory surrounding synapses demonstrated no differences in vivo (Supplemental Fig. 8A-C). Quantification of Vglut2 positive glomeruli number, intensity, and volume also showed no differences (Supplemental Fig. 9A-C). These findings were unexpected, especially given the large differences observed in culture. However, as we observed differences in synaptic function, it is possible there are differences in synaptic activity with a normal underlying synaptic density. Additional analysis of primary motor cortex in 1-month old C3KO mice also did not reveal any differences in synaptic density compared to WT controls (data not shown). The implications of these findings will be discussed in further detail below.

\section{Discussion}

Here, we present data generated from an unbiased behavioral assessment of C3KO mice, where we identified a novel locomotor phenotype characterized by a marked reduction in gait speed, increased locomotor bout duration, increased locomotor probability within individual active states, and gait ataxia. Prior studies have failed to identify motor phenotypes in C3KO mice. However, in these studies motor function was assessed by open field, SHIRPA, and rotarod assays [24]. In these assays, locomotion is confounded by other factors (e.g. novelty, handling, balance) and may thus be insensitive to detect changes in gait speed, locomotor patterns, and ataxia. In contrast to the open field assay, mice in the home cage system are freely moving within a habituated home space, thus providing a more face valid assessment of overall daily movement in the absence of forced testing. We further determined that the decreased gait speed observed in C3KO mice was not a result of significant limb weakness (as assessed by forelimb grip strength) nor joint arthritis (as assessed by visual inspection of the joint articular surface and cortical bone thickness at the knee tibial plateau). Quantification of daily ambulatory function, especially gait speed, is a critical measure of overall health as reduced gait speeds in the elderly are associated with poor healthcare outcomes [42]. 
The reduced gait speed and ataxia with preservation of movement bout initiation locomotor phenotype displayed by C3KO mice suggests a primarily cerebellar etiology [43]. The C3KO behavioral phenotype further was noted to resemble that observed in aged C57BL/ 6 mice. Of note, C3 cerebellar expression is significantly increased in aged mice. The U-shaped curve demonstrating locomotor impairments in mice with either C3 lack or C3 overexpression suggests that (similar to other physiological functions described by U-shaped output characteristics) C3 expression must remain within a defined range for optimal locomotor function [44]. Detailed assessment of other cerebellar-dependent behaviors (such motor learning, coordination, eye movements) may reveal further deficits.

C3 interactions with Factors $B$ and D generate C3a, which itself is rapidly cleaved to acylation-stimulating protein (ASP, also known as C3adesArg). ASP is well appreciated for its ability to stimulate triglyceride production from adipocytes and fibroblasts. We thus chose to examine body weights, body mass composition, adiposity, and metabolic rate in WT and C3KO mice. Concordant with other investigators, we found no differences in body weight between C3KO and WT mice $\left([27,45]\right.$; studying the $\mathrm{C} 3^{\mathrm{tm} 1 \mathrm{Hrc}}$ and the $\mathrm{C} 3 \mathrm{t}^{\mathrm{m} 1 \mathrm{Pkna}}$ knockout strains, respectively). C3KOs have been reported to have both decreased body weight and adiposity [46]; however, both 16-week-old WT and C3KO (C3 $\left.{ }^{\text {tm1Pkna }}\right)$ cohorts from this study were significantly heavier than our 3 mo old mice or the 4 month old mice of [45]. Sources of these discrepancies may reflect different transgenic strains of C3KO mice, different systems and calibration protocols for DEXA, and different diets.

To elucidate a mechanism for altered locomotor function in C3KO mice, we assessed synaptic density in cultures enriched for cerebellar granule cells. Primary cerebellar granule cell cultures are ideal models for studying developmental, pharmacologic, and functional properties of cerebellar internal granule cells [47, 48]. While granule cells occasionally synapse with local granule cells and inhibitory interneurons, most granule cell output forms parallel fibers targeted at the extensive Purkinje cell dendritic arbor. Thus, while primary granule cell culture may not be an ideal system to examine specific synaptic architectures, it is an appropriate model to examine regulation of synaptic protein production through measurement of Vglut1 or Vgat protein density.

Our data demonstrated increased excitatory and inhibitory synapse density in C3KO pCGC cultures after 6 days in vitro, but not at an earlier time point. The mechanisms underlying increased synaptic density in these cultures remain unknown. One potential mechanism is that increased in vivo synaptic density accompanying C3 loss resulted from reduced microglial pruning, which itself stemmed from loss of C3 tagged synapses [9]. Another potential mechanism is that astrocytic C3 release binding to neuronal surface C3aR in neuronal primary cultures depleted for microglia negatively impacts neuronal dendritic complexity and synaptic properties [49]. However, these mechanisms are probably not a strong drivers of our pCGC culture phenotypes, since both WT and C3KO pCGC cultures contain mostly neurons with low percentages of both astrocytes $(<1.0 \%)$ and microglia $(<1.0 \%)$. Finally, genotypic differences in synaptic density may be indicative of neuronal driven processes of synaptic regulation. For example, neuronal $\mathrm{C} 3 \mathrm{aR}$ binding to $\mathrm{C} 3$ ligands mediates dendritic and synaptic changes through activation of intraneuronal calcium signaling [49]. Similarly, treatment of cortical cultures with recombinant C3 reduced dendritic 
arborization and synapse density in vitro [49]. At this time, the processes leading to increased dendritic growth and complexity in C3KO primary cerebellar granule cell culture remain incompletely understood.

Our data also showed that cerebellar granule cells from C3KO mice had increased responsiveness to $\mathrm{KCl}$ induced depolarization. While this increased synaptic responsiveness may simply relate to the overall increase in dendrite number and complexity, further studies examining neuronal electrophysiologic properties will be required to confirm this hypothesis or alternatively identify alterations in synaptic protein complexes.

Our in vivo analysis of C3KO mice yielded the unexpected finding that synaptic densities in WT and C3KO mice did not differ in either the cerebellar molecular or internal granule cell layer. Based on our in vitro data we expected to observe increased synapse density in the molecular layer, the sole target region of cerebellar granule cell parallel fibers. One explanation for these differences is that changes observed in vitro are due to the reduced culture conditions where glial cells are extremely low in number, whereas within an in vivo system compensatory mechanisms are present. Cerebellar granule cells in culture synapse with other cerebellar granule cells and with a small population of inhibitory interneurons. A more physiological system and potential area of future study would be to use co-cultures of cerebellar granule cells and Purkinje cells. As C3KO granule cells showed increased calcium response to $\mathrm{KCl}$-induced depolarization, it is possible that cerebellar granule cell synapses in vivo have altered functions that underlie our observed baseline locomotor deficits. These increases in synaptic activity may ultimately result in increased Purkinje cell activation. Purkinje cells are rhythmically modulated during locomotor function with high activity during transitions between ipsilateral stance and swing phases, and low activity at mid-stance $[50,51]$. Altered Purkinje cell input may interfere with this process leading to impaired gait dynamics and ataxia.

In summary, loss of complement 3 , is accompanied by locomotor deficits and in vitro synaptic alterations in male C57BL/ 6 mice. As complement plays a role in regulating synapse density, it is possible that complement expression is increased as a compensatory mechanism for synaptic changes in the aging brain [52]. Our data demonstrates that C3 loss evokes slower gait speeds and ataxia, but not overt locomotor loss, findings similar to an aging phenotype. Identifying mechanisms underlying gait disturbances in older adults is critical for the development of novel therapeutic strategies, which have the potential to markedly improve quality of life. Further analysis of cerebellar roles of C3 may thus provide additional insights into age related locomotor deficits and potential therapies.

\section{Declarations}

Acknowledgements: We thank Megan Bosch, Ph.D., for assistance with calcium imaging studies.

Funding: This work was supported by the National Institutes of Health/National Institute on Aging grant \#AG031158 (SJB) and by the Vada Kinman Alzheimer's Research Fund (NWD).

Conflicts of interest/Competing interests: The authors report no conflicts of interest. 
Ethics approval: All studies were performed in full concordance with both institutional and federal regulations regarding animal care and use; our research protocol was approved by the UNMC Institutional Animal Care and Use Committee (IACUC).

Consent to participate: not applicable.

Consent for publication: not applicable.

Availability of data and material: The datasets generated and/or analyzed during the current study are available in the University of Nebraska Digital Commons repository.

Code availability: Not applicable.

Author's contributions: NWD performed behavioral, molecular biology, and primary neuronal culture experiments, data analysis, manuscript drafting, preparation, review; TRC performed behavioral experiments, data analysis, manuscript review; GZ performed and provided analytical support for microtomography experiments, participated in manuscript preparation and review; DW participated in manuscript preparation and review; JA performed confocal microscopy data analysis, manuscript editing and review; SJB performed behavioral and microtomography data analysis, manuscript editing and review.

\section{References}

1. Campbell JN, Macosko EZ, Fenselau H, Pers TH, Lyubetskaya A, Tenen D, Goldman M, Verstegen AM, Resch JM, McCarroll SA, Rosen ED, Lowell BB, Tsai LT (2017) A molecular census of arcuate hypothalamus and median eminence cell types. Nat Neurosci 20 (3):484-496. doi:10.1038/nn.4495

2. Fischer B, Schmoll H, Riederer P, Bauer J, Platt D, Popa-Wagner A (1995) Complement C1q and C3 mRNA expression in the frontal cortex of Alzheimer's patients. J Mol Med (Berl) 73 (9):465-471

3. Head E, Azizeh BY, Lott IT, Tenner AJ, Cotman CW, Cribbs DH (2001) Complement association with neurons and beta-amyloid deposition in the brains of aged individuals with Down Syndrome. Neurobiol Dis 8 (2):252-265. doi:10.1006/nbdi.2000.0380

4. McGeer PL, Akiyama H, Itagaki S, McGeer EG (1989) Activation of the classical complement pathway in brain tissue of Alzheimer patients. Neurosci Lett 107 (1-3):341-346

5. Terai K, Walker DG, McGeer EG, McGeer PL (1997) Neurons express proteins of the classical complement pathway in Alzheimer disease. Brain Res 769 (2):385-390. doi:10.1016/s00068993(97)00849-4

6. Thomas A, Gasque P, Vaudry D, Gonzalez B, Fontaine M (2000) Expression of a complete and functional complement system by human neuronal cells in vitro. Int Immunol 12 (7):1015-1023. doi:10.1093/intimm/12.7.1015

7. Yasojima K, Schwab C, McGeer EG, McGeer PL (1999) Up-regulated production and activation of the complement system in Alzheimer's disease brain. Am J Pathol 154 (3):927-936. doi:10.1016/S0002- 
9440(10)65340-0

8. Bialas AR, Stevens B (2013) TGF-beta signaling regulates neuronal C1q expression and developmental synaptic refinement. Nat Neurosci 16 (12):1773-1782. doi:10.1038/nn.3560

9. Stevens B, Allen NJ, Vazquez LE, Howell GR, Christopherson KS, Nouri N, Micheva KD, Mehalow AK, Huberman AD, Stafford B, Sher A, Litke AM, Lambris JD, Smith SJ, John SW, Barres BA (2007) The classical complement cascade mediates CNS synapse elimination. Cell 131 (6):1164-1178. doi:10.1016/j.cell.2007.10.036

10. Luchena C, Zuazo-lbarra J, Alberdi E, Matute C, Capetillo-Zarate E (2018) Contribution of Neurons and Glial Cells to Complement-Mediated Synapse Removal during Development, Aging and in Alzheimer's Disease. Mediators Inflamm 2018:2530414. doi:10.1155/2018/2530414

11. Luchena C, Zuazo-Ibarra J, Alberdi E, Matute C, Capetillo-Zarate E (2019) Corrigendum to "Contribution of Neurons and Glial Cells to Complement-Mediated Synapse Removal during Development, Aging and in Alzheimer's Disease". Mediators Inflamm 2019:7539620. doi:10.1155/2019/7539620

12. Shinjyo N, Stahlberg A, Dragunow M, Pekny M, Pekna M (2009) Complement-derived anaphylatoxin C3a regulates in vitro differentiation and migration of neural progenitor cells. Stem Cells 27 (11):2824-2832. doi:10.1002/stem.225

13. Rahpeymai Y, Hietala MA, Wilhelmsson U, Fotheringham A, Davies I, Nilsson AK, Zwirner J, Wetsel RA, Gerard C, Pekny M, Pekna M (2006) Complement: a novel factor in basal and ischemia-induced neurogenesis. EMBO J 25 (6):1364-1374. doi:10.1038/sj.emboj.7601004

14. Gorelik A, Sapir T, Haffner-Krausz R, Olender T, Woodruff TM, Reiner O (2017) Developmental activities of the complement pathway in migrating neurons. Nat Commun 8:15096. doi: $10.1038 /$ ncomms 15096

15. Gorelik A, Sapir T, Ben-Reuven L, Reiner O (2018) Complement C3 Affects Rac1 Activity in the Developing Brain. Front Mol Neurosci 11:150. doi:10.3389/fnmol.2018.00150

16. Benard M, Gonzalez BJ, Schouft MT, Falluel-Morel A, Vaudry D, Chan P, Vaudry H, Fontaine M (2004) Characterization of $\mathrm{C} 3 \mathrm{a}$ and $\mathrm{C} 5 \mathrm{a}$ receptors in rat cerebellar granule neurons during maturation. Neuroprotective effect of C5a against apoptotic cell death. J Biol Chem 279 (42):43487-43496. doi:10.1074/jbc.M404124200

17. Benard M, Raoult E, Vaudry D, Leprince J, Falluel-Morel A, Gonzalez BJ, Galas L, Vaudry H, Fontaine $\mathrm{M}$ (2008) Role of complement anaphylatoxin receptors (C3aR, C5aR) in the development of the rat cerebellum. Mol Immunol 45 (14):3767-3774. doi:10.1016/j.molimm.2008.05.027

18. Berg A, Zelano J, Stephan A, Thams S, Barres BA, Pekny M, Pekna M, Cullheim S (2012) Reduced removal of synaptic terminals from axotomized spinal motoneurons in the absence of complement C3. Exp Neurol 237 (1):8-17. doi:10.1016/j.expneurol.2012.06.008

19. Stokowska A, Atkins AL, Moran J, Pekny T, Bulmer L, Pascoe MC, Barnum SR, Wetsel RA, Nilsson JA, Dragunow M, Pekna M (2017) Complement peptide C3a stimulates neural plasticity after experimental brain ischaemia. Brain 140 (2):353-369. doi:10.1093/brain/aww314 
20. Chu Y, Jin X, Parada I, Pesic A, Stevens B, Barres B, Prince DA (2010) Enhanced synaptic connectivity and epilepsy in C1q knockout mice. Proc Natl Acad Sci U S A 107 (17):7975-7980. doi:10.1073/pnas.0913449107

21. Schafer DP, Lehrman EK, Kautzman AG, Koyama R, Mardinly AR, Yamasaki R, Ransohoff RM, Greenberg ME, Barres BA, Stevens B (2012) Microglia sculpt postnatal neural circuits in an activity and complement-dependent manner. Neuron 74 (4):691-705. doi:10.1016/j.neuron.2012.03.026

22. Perez-Alcazar M, Daborg J, Stokowska A, Wasling P, Bjorefeldt A, Kalm M, Zetterberg H, Carlstrom KE, Blomgren K, Ekdahl CT, Hanse E, Pekna M (2014) Altered cognitive performance and synaptic function in the hippocampus of mice lacking C3. Exp Neurol 253:154-164. doi:10.1016/j.expneurol.2013.12.013

23. van Beek J, Nicole O, Ali C, Ischenko A, MacKenzie ET, Buisson A, Fontaine M (2001) Complement anaphylatoxin $\mathrm{C} 3 \mathrm{a}$ is selectively protective against NMDA-induced neuronal cell death. Neuroreport 12 (2):289-293

24. Shi Q, Colodner KJ, Matousek SB, Merry K, Hong S, Kenison JE, Frost JL, Le KX, Li S, Dodart JC, Caldarone BJ, Stevens B, Lemere CA (2015) Complement C3-Deficient Mice Fail to Display AgeRelated Hippocampal Decline. J Neurosci 35 (38):13029-13042. doi:10.1523/JNEUROSCI.169815.2015

25. Hong S, Beja-Glasser VF, Nfonoyim BM, Frouin A, Li S, Ramakrishnan S, Merry KM, Shi Q, Rosenthal A, Barres BA, Lemere CA, Selkoe DJ, Stevens B (2016) Complement and microglia mediate early synapse loss in Alzheimer mouse models. Science 352 (6286):712-716. doi:10.1126/science.aad8373

26. Murray I, Havel PJ, Sniderman AD, Cianflone K (2000) Reduced body weight, adipose tissue, and leptin levels despite increased energy intake in female mice lacking acylation-stimulating protein. Endocrinology 141 (3):1041-1049. doi:10.1210/endo.141.3.7364

27. Murray I, Sniderman AD, Havel PJ, Cianflone K (1999) Acylation stimulating protein (ASP) deficiency alters postprandial and adipose tissue metabolism in male mice. J Biol Chem 274 (51):36219-36225

28. Bonasera SJ, Arikkath J, Boska MD, Chaudoin TR, DeKorver NW, Goulding EH, Hoke TA, Mojtahedzedah V, Reyelts CD, Sajja B, Schenk AK, Tecott LH, Volden TA (2016) Age-related changes in cerebellar and hypothalamic function accompany non-microglial immune gene expression, altered synapse organization, and excitatory amino acid neurotransmission deficits. Aging (Albany NY) 8 (9):2153-2181. doi:10.18632/aging.101040

29. Wessels MR, Butko P, Ma M, Warren HB, Lage AL, Carroll MC (1995) Studies of group B streptococcal infection in mice deficient in complement component $\mathrm{C} 3$ or $\mathrm{C} 4$ demonstrate an essential role for complement in both innate and acquired immunity. Proc Natl Acad Sci U S A 92 (25):11490-11494. doi:10.1073/pnas.92.25.11490

30. Sheerin NS, Abe K, Risley P, Sacks SH (2006) Accumulation of immune complexes in glomerular disease is independent of locally synthesized c3. J Am Soc Nephrol 17 (3):686-696. doi:10.1681/ASN.2004070515 
31. Kiang A, Hartman ZC, Everett RS, Serra D, Jiang H, Frank MM, Amalfitano A (2006) Multiple innate inflammatory responses induced after systemic adenovirus vector delivery depend on a functional complement system. Mol Ther 14 (4):588-598. doi:10.1016/j.ymthe.2006.03.024

32. Ad vectors in C3KO mice (2006) National Center for Biotechnology Information (NCBI).

33. Goulding EH, Schenk AK, Juneja P, MacKay AW, Wade JM, Tecott LH (2008) A robust automated system elucidates mouse home cage behavioral structure. Proc Natl Acad Sci U S A 105 (52):2057520582. doi:10.1073/pnas.0809053106

34. Parkison SA, Carlson JD, Chaudoin TR, Hoke TA, Schenk AK, Goulding EH, Perez LC, Bonasera SJ (2012) A low-cost, reliable, high-throughput system for rodent behavioral phenotyping in a home cage environment. Conf Proc IEEE Eng Med Biol Soc 2012:2392-2395.

doi:10.1109/EMBC.2012.6346445

35. Rosin PL (1999) Measuring rectangularity. Machine Vision Appl 11:191-196

36. Hatten ME, Gao W-Q, Morrison ME, Mason CA (1998) The cerebellum: purification and coculture of identified populations. In: Banker G, Goslin K (eds) Culturing nerve cells. MIT, Cambridge MA, pp 419459

37. Beaudoin GM, 3rd, Lee SH, Singh D, Yuan Y, Ng YG, Reichardt LF, Arikkath J (2012) Culturing pyramidal neurons from the early postnatal mouse hippocampus and cortex. Nat Protoc 7 (9):17411754. doi:10.1038/nprot.2012.099

38. Schneider CA, Rasband WS, Eliceiri KW (2012) NIH Image to ImageJ: 25 years of image analysis. Nat Methods 9 (7):671-675

39. Schneidereit D, Vass H, Reischl B, Allen RJ, Friedrich O (2016) Calcium Sensitive Fluorescent Dyes Fluo-4 and Fura Red under Pressure: Behaviour of Fluorescence and Buffer Properties under Hydrostatic Pressures up to 200 MPa. PLoS One 11 (10):e0164509. doi:10.1371/journal.pone.0164509

40. Benjamini Y, Hochberg Y (1995) Controlling the false discovery rate: a practical and powerful approach to multiple testing. Journal of the Royal Statistical Society Series B (Methodological) 57:289-300

41. Tschop MH, Speakman JR, Arch JR, Auwerx J, Bruning JC, Chan L, Eckel RH, Farese RV, Jr., Galgani JE, Hambly C, Herman MA, Horvath TL, Kahn BB, Kozma SC, Maratos-Flier E, Muller TD, Munzberg H, Pfluger PT, Plum L, Reitman ML, Rahmouni K, Shulman GI, Thomas G, Kahn CR, Ravussin E (2011) A guide to analysis of mouse energy metabolism. Nat Methods 9 (1):57-63. doi:10.1038/nmeth. 1806

42. Studenski S, Perera S, Patel K, Rosano C, Faulkner K, Inzitari M, Brach J, Chandler J, Cawthon P, Connor EB, Nevitt M, Visser M, Kritchevsky S, Badinelli S, Harris T, Newman AB, Cauley J, Ferrucci L, Guralnik J (2011) Gait speed and survival in older adults. JAMA 305 (1):50-58. doi:10.1001/jama.2010.1923

43. Nadkarni NK, Nunley KA, Aizenstein H, Harris TB, Yaffe K, Satterfield S, Newman AB, Rosano C, Health ABCS (2014) Association between cerebellar gray matter volumes, gait speed, and information- 
processing ability in older adults enrolled in the Health ABC study. J Gerontol A Biol Sci Med Sci 69 (8):996-1003. doi:10.1093/gerona/glt151

44. Calabrese EJ, Baldwin LA (2001) U-shaped dose-responses in biology, toxicology, and public health. Annu Rev Public Health 22:15-33. doi:10.1146/annurev.publhealth.22.1.15

45. Paglialunga S, Fisette A, Yan Y, Deshaies Y, Brouillette JF, Pekna M, Cianflone K (2008) Acylationstimulating protein deficiency and altered adipose tissue in alternative complement pathway knockout mice. Am J Physiol Endocrinol Metab 294 (3):E521-529. doi:10.1152/ajpendo.00590.2007

46. Persson L, Boren J, Robertson AK, Wallenius V, Hansson GK, Pekna M (2004) Lack of complement factor $\mathrm{C} 3$, but not factor B, increases hyperlipidemia and atherosclerosis in apolipoprotein E-/- lowdensity lipoprotein receptor-/- mice. Arterioscler Thromb Vasc Biol 24 (6):1062-1067. doi:10.1161/01.ATV.0000127302.24266.40

47. Komuro H, Yacubova E (2003) Recent advances in cerebellar granule cell migration. Cell Mol Life Sci 60 (6):1084-1098. doi:10.1007/s00018-003-2248-z

48. Bilimoria PM, Bonni A (2008) Cultures of cerebellar granule neurons. CSH Protoc 2008:pdb prot5107. doi:10.1101/pdb.prot5107

49. Lian H, Yang L, Cole A, Sun L, Chiang AC, Fowler SW, Shim DJ, Rodriguez-Rivera J, Taglialatela G, Jankowsky JL, Lu HC, Zheng H (2015) NFkappaB-activated astroglial release of complement C3 compromises neuronal morphology and function associated with Alzheimer's disease. Neuron 85 (1):101-115. doi:10.1016/j.neuron.2014.11.018

50. Armstrong DM, Edgley SA (1988) Discharges of interpositus and Purkinje cells of the cat cerebellum during locomotion under different conditions. J Physiol 400:425-445. doi:10.1113/jphysiol.1988.sp017130

51. Edgley SA, Lidierth M (1988) Step-related discharges of Purkinje cells in the paravermal cortex of the cerebellar anterior lobe in the cat. J Physiol 401:399-415. doi:10.1113/jphysiol.1988.sp017169

52. Stephan AH, Madison DV, Mateos JM, Fraser DA, Lovelett EA, Coutellier L, Kim L, Tsai HH, Huang EJ, Rowitch DH, Berns DS, Tenner AJ, Shamloo M, Barres BA (2013) A dramatic increase of C1q protein in the CNS during normal aging. J Neurosci 33 (33):13460-13474. doi:10.1523/JNEUROSCI.133313.2013 